\title{
THE MANAGEMENT OF PRE SCHOOL TOWARDS ACCREDITATION STANDARDS
}

\author{
Nurhaida Selian \\ Sekolah Tinggi Agama Islam Negeri Bengkalis, Riau, Indonesia \\ Email: nurhaidah832@gmail.com
}

DOI: 10.35445/alishlah.v11i2.150

Accepted: September $30^{\text {th }}, 2019$. Approved: November $12^{\text {th }}, 2019$. Published:

December $30^{\text {th }}, 2019$

\begin{abstract}
The research is conducted by the rampant growth of PAUD institutions in the regions but has not been accompanied by efforts to fulfill quality according to national quality standards so that they do not meet accreditation assessments. The objective of this research is to determine PAUD management system in national standards in Bengkalis District and to find out the dominant factors that do not meet national standards in PAUD management systems towards accreditation in Bengkalis District. The method of this reaearch is descriptive with using simple random technique. The data collection method is by observation and documentation. The results showed that the PAUD management system in Bengkalis District that fulfilled the national standard criteria passed the accreditation of $80 \%$ and $20 \%$ had not passed yet. The dominant factors that have not been fulfilled in the national standard criteria for PAUD management systems in Bengkalis District are: PAUD units do not yet have a personnel task description according to the organizational structure chart; PAUD unit does not have an annual work plan that contains elements of objectives, targets, policies, program activities, and financing; not enough aspects of development in the implementation of daily learning separately in the PAUD program; does not have a weekly activity plan; PAUD units does not yet have a holistic integrative program that includes health, nutrition, educational stimulation, care, and protection.
\end{abstract}

Keywords: Accreditation, PAUD, Quality, Management 
Al-Ishlah: Jurnal Pendidikan - ISSN: 2087-949o (p); 2597-940X (e)

Vol. 11, No. 2 (2019)

\title{
SISTEM MANAJEMEN PENGELOLAAN PAUD MENUJU AKREDITASI
}

\begin{abstract}
Abstrak
Penelitian ini dilatarbelakangi oleh maraknya pertumbuhan satuan lembaga PAUD di berbagai daerah, tetapi belum diikuti dengan upaya pemenuhan kualitas sesuai standar mutu nasional sehingga tidak memenuhi penilaian akreditasi. Tujuan penelitian ini adalah untuk mengetahui sistem pengelolaan PAUD dalam standar nasional di Kecamatan Bengkalis dan faktor-faktor dominan yang tidak memenuhi standar nasional dalam sistem pengelolaan PAUD menuju akreditasi di Kecamatan Bengkalis. Penelitian dilakukan dengan metode deskriptif melalui teknik pengumpulan data simple random. Metode pengumpulan data dilakukan dengan observasi dan dokumentasi. Hasil penelitian menunjukkan bahwa sistem pengelolaan PAUD di Kecamatan Bengkalis yang memenuhi kriteria standar nasional lulus akreditasi sebesar $80 \%$ dan yang belum lulus sebesar 20\%. Faktor dominan yang belum terpenuhi dalam kriteria standar nasional sistem pengelolaan PAUD di Kecamatan Bengkalis adalah: satuan PAUD belum memiliki deskripsi tugas personalia sesuai bagan struktur organisasi; satuan PAUD belum memiliki rencana kerja tahunan yang mengandung unsur tujuan, target, sasaran, kebijakan, program kegiatan, dan pembiayaan; aspek-aspek pengembangan pada pelaksanaan pembelajaran harian secara terpisah dalam program PAUD belum mencukupi; satuan PAUD tidak memiliki rencana kegiatan mingguan (RKM); satuan PAUD belum memiliki program holistic integrative yang mencakup kesehatan, gizi, rangsangan pendidikan, pengasuhan, dan perlindungan.
\end{abstract}

Kata Kunci: Akreditasi, PAUD, Mutu, Pengelolaan

\section{PENDAHULUAN}

Maraknya pendirian lembaga pendidikan anak usia dini (PAUD) belakangan ini disebabkan peluang ekonomi yang terbentuk dari kebutuhan para orang tua untuk menitipkan anak di lembaga yang aman, nyaman, dan sehat serta dapat membentuk karakter anak. Kebutuhan ini semakin meningkat karena tren masa kini kedua orang tua (ayah dan ibu) pada umumnya memiliki karier. Oleh sebab itu, mereka merasa nyaman bila menitipkan anak yang masih balita di lembaga-lembaga PAUD. Didorong oleh program pemerintah yang mengucurkan anggaran untuk membantu pendirian PAUD, menyebabkan banyak PAUD pemula yang berdiri dengan cepat.

Kebanyakan lembaga PAUD terintegrasi dengan kelompok bermain dan taman kanak-kanak (TK). Inisiator pendiri PAUD biasanya berasal dari kalangan pribadi, kader PKK, pengurus posyandu, dan pengurus rukun warga (RW) atau 
Al-Ishlah: Jurnal Pendidikan - ISSN: 2087-949o (p); 2597-940X (e)

Vol. 11, No. 2 (2019)

yayasan tertentu (Sumaryanto, 2014:534). Di lapangan banyak ditemukan pendirian PAUD yang tidak sesuai dengan prosedur dan standar mutu yang ditetapkan dalam standar nasional sehingga dalam pelaksanaan programnya tidak dapat memenuhi tujuan utama dari pendirian PAUD tersebut. Pendirian PAUD yang tidak sesuai standar nasional ini disebut tidak layak untuk melaksanakan program pendidikan. Pengelolaan yang belum optimal disebabkan pendirian PAUD yang tergesa-gesa, contohnya pada pertengahan tahun 2014, karena adanya program dari pemerintah yaitu satu desa satu PAUD (Mukminin dan Cahyani, 2017: 48).

UU No. 20 Tahun 2003 tentang Sistem Pendidikan Nasional Pasal 62 butir 1 menyatakan bahwa setiap satuan pendidikan formal dan nonformal yang didirikan wajib memperoleh izin pemerintah atau pemerintah daerah. Dengan demikian, pendirian lembaga PAUD walaupun didorong oleh pemerintah tetap harus memiliki izin. Dalam hal pemberian izin, lembaga pendidikan tersebut harus sudah lolos uji terhadap kriteria-kriteria baku yang sudah ditetapkan dalam peraturan perundang-undangan. Kriteria-kriteria tersebut merupakan penjamin mutu lembaga pendidikan.

Fatimah dan Rohmah (2016: 249) menyatakan bahwa pendidikan anak usia dini sangatlah penting, karena kapabilitas kecerdasan orang dewasa terjadi ketika berusia 4 tahun, kemudian jaringan otak berkembang dengan pesat ketika berusia 8 tahun, dan akan mencapai puncak kecerdasan pada usia 18 tahun. Masa perkembangan kecerdasan anak sering disebut dengan masa emas yang hanya datang sekali, sehingga apabila terlewatkan berarti habislah peluangnya.

Dengan demikian, kehadiran lembaga PAUD yang bermutu merupakan hal penting dan tidak dapat diremehkan. Pembentukan karakter anak yang siap dalam menghadapai tantangan yang berikutnya harus dibangun semasa anak masih mengikuti program pendidikan di lembaga PAUD. Kelayakan program pendidikan menjadi hal penting agar tidak keluar dari tujuan utama pendirian program atau satuan pendidikan.

Selanjutnya, hal yang diperlukan dalam pengelolaan PAUD adalah adanya standar PAUD. Standar PAUD bertujuan menjamin mutu pendidikan anak usia dini dalam rangka memberikan landasan untuk melakukan stimulan dalam pendidikan guna membantu pertumbuhan dan perkembangan jasmani dan rohani sesuai dengan tingkat pencapaian perkembangan anak; mengoptimalkan perkembangan anak secara holistik dan integratif; dan mempersiapkan pembentukan sikap, pengetahuan, dan keterampilan anak (Permendikbud No. 137 Tahun 2014).

Sebuah lembaga PAUD yang bermutu dinyatakan dengan nilai akreditasi. Akreditasi dilakukan untuk menentukan kelayakan program dan satuan pendidikan, termasuk PAUD. Dalam mempersiapkan sebuah lembaga yang 
Al-Ishlah: Jurnal Pendidikan - ISSN: 2087-949o (p); 2597-940X (e)

Vol. 11, No. 2 (2019)

terakreditasi, banyak persyaratan dan kriteria yang harus dipenuhi. Semua persyaratan dan kriteria ini tergabung dalam sebuah konsep sistem pengelolaan PAUD yang terpadu.

Kabupaten Bengkalis, Provinsi Riau, melalui program Bunda PAUD mencanangkan Program Satu Desa Satu PAUD dengan anggaran dari APBD untuk mendorong terbentuknya lembaga PAUD di setiap desa. Dalam pelaksanaan program ini, istri kepala desa ditunjuk sebagai bunda PAUD di desanya. Kecamatan Bengkalis, salah satu kecamatan di Kabupaten Bengkalis, merupakan suatu daerah berkembang yang sedang getol untuk mendirikan PAUD pada setiap desa. Namun, karena masih kurangnya pengetahuan masyarakat, terutama pihak lembaga pengelola PAUD, mengenai kriteria dan persyaratan akreditasi, pendirian lembaga PAUD masih banyak yang belum sesuai dengan standar kelayakan program pendidikan. Kesiapan desa-desa dalam memenuhi standar yang ditetapkan peraturan pemerintah masih belum memadai.

Penelitian ini akan memaparkan kondisi kesiapan lembaga-lembaga PAUD di Kecamatan Bengkalis dalam memenuhi kriteria akreditasi. Penelitian ini penting untuk dilaksanakan dalam rangka mempersiapkan Kecamatan Bengkalis memiliki lembaga-lembaga PAUD yang terakreditasi sesuai dengan standar mutu nasional. Tujuan penelitian ini adalah untuk mengetahui sistem pengelolaan PAUD dalam standar nasional di Kecamatan Bengkalis dan untuk mengetahui faktor-faktor dominan yang tidak memenuhi standar nasional dalam sistem pengelolaan PAUD menuju akreditasi di Kecamatan Bengkalis.

Partisipasi lembaga PAUD yang ada di sekitar Kecamatan Bengkalis cukup baik, tetapi dalam menyiapkan seluruh adminstrasi akreditasi, baik yang disiapkan oleh pengelola maupun guru, masih sangat minim. Oleh karena itu, dari observasi awal peneliti menemukan banyak faktor yang menjadi kendala lembaga dalam mengikuti akreditasi, yakni sistem manajerial lembaga PAUD yang rendah dan sistem administrasi yang tidak terdokumentasikan dengan baik.

Dalam penilaian akreditasi lembaga PAUD terdapat 22 butir status major. Butir-butir tersebut merupakan jabaran dari 8 standar akreditasi PAUD sesuai dengan Permendikbud No. 137 Tahun 2014. Butir-butir itu merupakan dasar penilaian dalam menentukan sebuah lembaga PAUD dapat memenuhi akreditasi atau tidak. Sebuah lembaga PAUD dinyatakan lulus bila minimal memenuhi 17 dari 22 butir yang ada. Bila kurang dari 17, lembaga tersebut dinyatakan tidak memenuhi standar akreditasi (tidak lulus). Lembaga-lembaga PAUD yang dijadikan sampel akan dinilai berdasarkan butir-butir major tersebut sehingga dapat diketahui persentase pengelolaan PAUD yang memenuhi syarat akreditasi. Kemudian, dari hasil penghitungan tersebut, juga dapat dilihat faktor-faktor dominan yang menjadi kelemahan umum pada berbagai lembaga PAUD sehingga dapat dilakukan langkah perbaikan untuk masa yang akan datang. 
Al-Ishlah: Jurnal Pendidikan - ISSN: 2087-949o (p); 2597-940X (e)

Vol. 11, No. 2 (2019)

\section{METODE PENELITIAN}

Penelitian dilaksanakan pada September sampai dengan November 2018. Lokasi penelitian adalah lembaga PAUD yang ada di Kecamatan Bengkalis, Kabupaten Bengkalis. Pendekatan penelitian dilakukan secara deskriptif. Metode pengumpulan data dilakukan dengan cara observasi dan dokumentasi. Analisis data menggunakan pendekatan kuantitatif deskriptif dengan memanfaatkan analisis statistik deskriptif. Sumber data adalah data primer dan data sekunder. Data primer yang diperlukan dalam penelitian ini adalah pengambilan sampel dokumen 15 PAUD secara langsung dengan kuesioner yang diberikan kepada 15 lembaga. Data sekunder berupa keadaan geografi 15 lembaga serta kondisi administrsi lembaga dari Dinas Pendidikan Kabupaten Bengkalis.

Populasi dalam penelitian ini adalah keseluruhan lembaga PAUD yang ada di Kecamatan Bengkalis. Menurut data yang ada di Dinas Pendidikan Kabupaten Bengkalis, pada 2018, jumlah lembaga PAUD yang terdaftar di Kecamatan Bengkalis adalah 67 . Sampel yang diambil adalah sebesar $20 \%$ dari populasi yaitu 15 lembaga. Teknik pengambilan sampel adalah dengan menggunakan simple random.

Dokumentasi dan observasi digunakan untuk mengukur sistem pengelolaan PAUD, yakni dengan mencentang dokumen yang dimiliki sesuai dengan 22 butir status major dalam rubrik penilaian akreditasi PAUD.

Tabel 1 Konsep Operasional Penilaian Akreditasi PAUD

\begin{tabular}{|c|c|c|c|c|}
\hline No. & Variabel & Konsep & Indikator & Skala \\
\hline 1. & $\begin{array}{l}\text { Standar } \\
\text { Tingkat } \\
\text { Pencapaian } \\
\text { Perkembangan }\end{array}$ & $\begin{array}{l}\text { 1. Dokumen pencapaian } \\
\text { perkembangan anak } \\
\text { berdasarkan atas } 6 \text { (enam) } \\
\text { aspek lingkup perkembangan. } \\
\text { 2. Dokumen pencapaian } \\
\text { perkembangan anak sesuai } \\
\text { kelompok usia. }\end{array}$ & $\begin{array}{c}\text { Permendikbud } \\
\text { No. } 137 \text { Tahun } \\
2014\end{array}$ & Interval \\
\hline 2. & Standarisi & $\begin{array}{l}\text { 1. Struktur kurikulum dan } \\
\text { penetapannya. } \\
\text { 2. Kesesuaian program PAUD } \\
\text { memberikan layanan menurut } \\
\text { kelompok usia. } \\
\text { 3. Aspek-aspek } \\
\text { pengembangan pada }\end{array}$ & $\begin{array}{c}\text { Permendikbud } \\
\text { No. } 137 \text { Tahun } \\
2014\end{array}$ & Interval \\
\hline
\end{tabular}


Al-Ishlah: Jurnal Pendidikan - ISSN: 2087-949o (p); 2597-940X (e)

Vol. 11, No. 2 (2019)

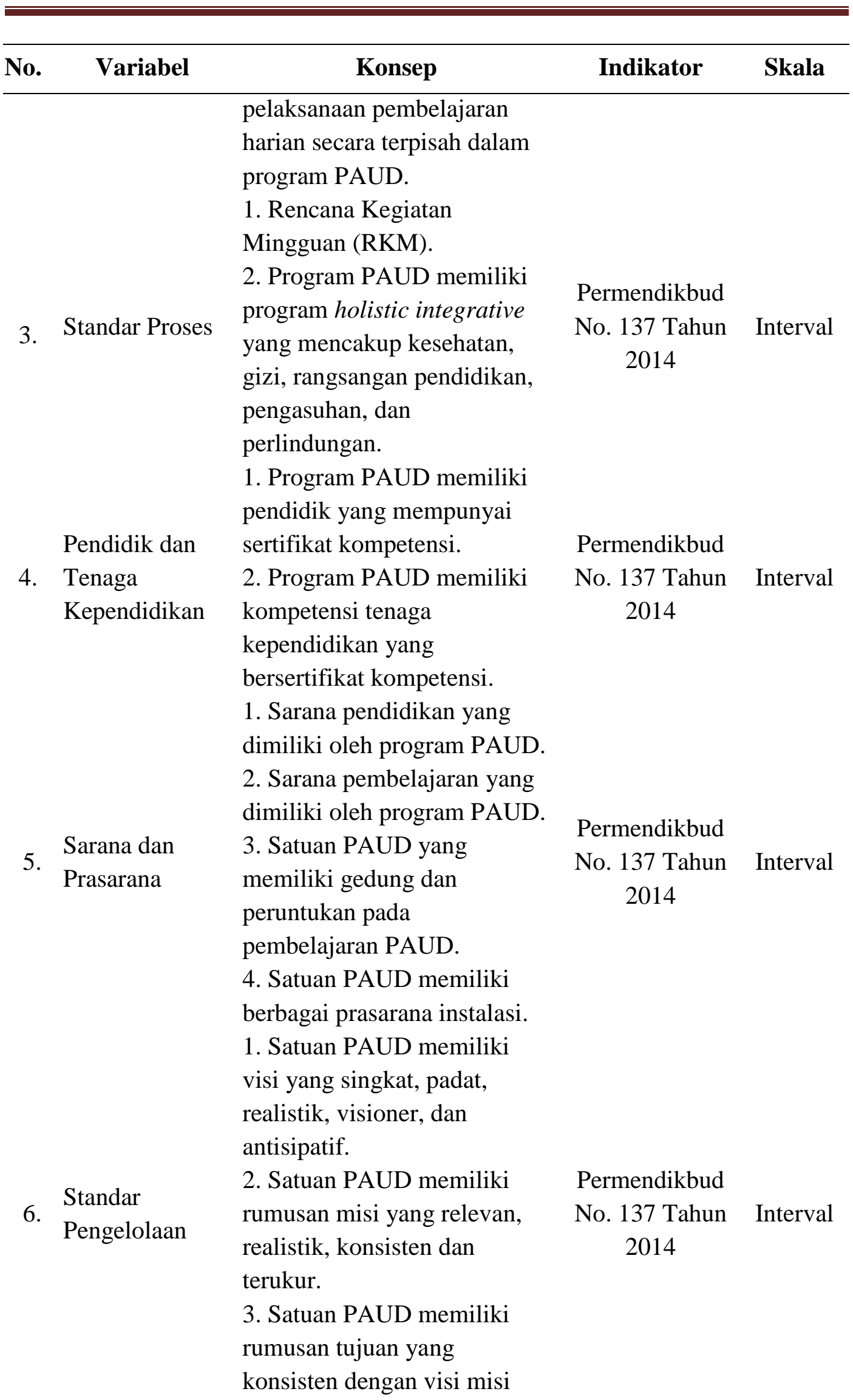


Al-Ishlah: Jurnal Pendidikan - ISSN: 2087-949o (p); 2597-940X (e)

Vol. 11, No. 2 (2019)

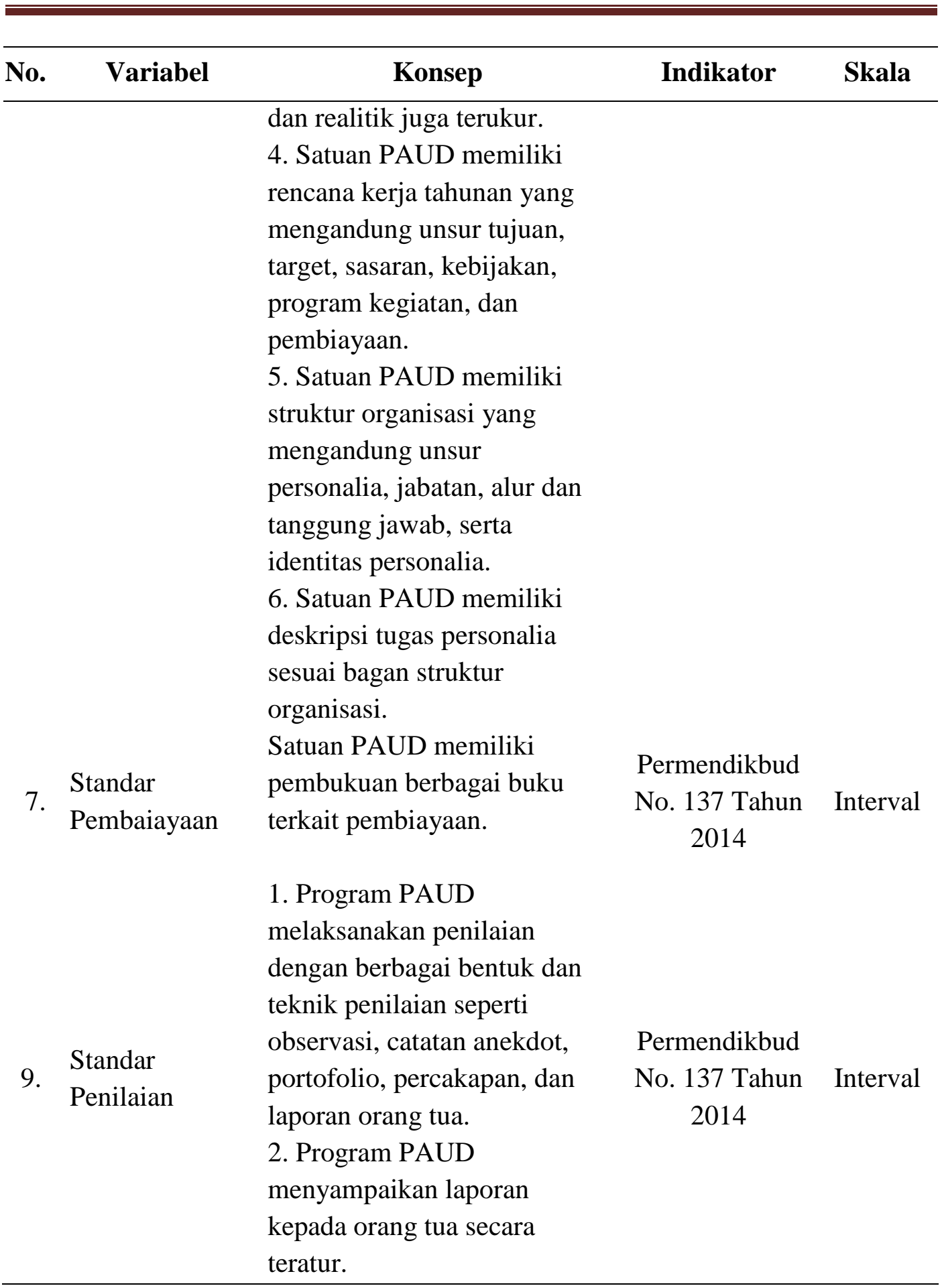

Data hasil observasi dan dokumentasi dihitung dengan memeriksa setiap item yang akan diberi nilai 0 dan 1 . Bernilai 0 jika setiap butiran tidak memenuhi kesesuaian minimal dalam standar. Bernilai 1 jika setiap butiran menunjukkan kesesuaian minimal dalam standar. Bila memenuhi minimal 17 poin dari 22 poin tersebut, lembaga PAUD tersebut dinyatakan memenuhi kriteria lulus akreditasi. 
Al-Ishlah: Jurnal Pendidikan - ISSN: 2087-949o (p); 2597-940X (e)

Vol. 11, No. 2 (2019)

Sementara, bila kurang dari 17 poin, lembaga PAUD tersebut dinyatakan tidak lulus kriteria akreditasi.

Faktor-faktor utama yang belum terpenuhi dari berbagai lembaga PAUD di Kecamatan Bengkalis dapat dilihat dari modus butir yang bernilai 0 (nol). Dari faktor-faktor dominan ini dapat ditarik kesimpulan bahwa perlu adanya pembinaan terhadap lembaga-lembaga PAUD sehingga kesempurnaan mutu dari lembaga PAUD di Kecamatan Bengkalis dapat ditingkatkan.

\section{HASIL DAN PEMBAHASAN}

Pengamatan dilakukan langsung di lokasi sampel sebanyak lima belas lembaga PAUD. Pengamatan dilakukan dengan melihat kelengkapan dokumen yang dimiliki oleh lembaga PAUD. Penilaian dilakukan dengan menilai kesesuaian minimal dalam 22 butir status major dalam rubrik penilaian PAUD. Dari hasil penghitungan tersebut, terdapat dua belas lembaga PAUD yang memenuhi standar nasional kriteria lulus akreditasi dan tiga lembaga yang masih belum lulus untuk memenuhi standar nasional kriteria kelulusan akreditasi. Dengan demikian, dapat dihitung persentase kelulusan lembaga PAUD di Kecamatan Bengkalis adalah sebesar $80 \%$ dan persentase ketidaklulusan standar nasional akreditasi adalah $20 \%$.

Dari tabel pada Lampiran 2 dapat dilihat bahwa modus butir yang bernilai 0 (nol) diurutkan dari terendah adalah pada butir nomor 19, 16, 5, 6, dan 7. Butir 19 berisikan satuan PAUD memiliki deskripsi tugas personalia sesuai bagan struktur organisasi. Butir 17 berisikan satuan PAUD memiliki rencana kerja tahunan yang mengandung unsur tujuan, target, sasaran, kebijakan, program kegiatan, dan pembiayaan. Butir 5 berisikan aspek-aspek pengembangan pada pelaksanaan pembelajaran harian secara terpisah dalam program PAUD. Butir 6 berisikan rencana kegiatan mingguan (RKM). Butir 7 berisikan program PAUD yang memiliki program holistic integrative yang mencakup kesehatan, gizi, rangsangan pendidikan, pengasuhan, dan perlindungan.

Dalam menyongsong era revolusi industry 4.0, lembaga PAUD yang terakreditasi di Kecamatan Bengkalis masih harus banyak berbenah. Lembaga PAUD yang belum memenuhi kriteria kelulusan harus segera mendapatkan pembinaan. Pembinaan ini perlu dilakukan untuk meningkatkan mutu pendidikan PAUD sehingga keluaran dari lembaga tersebut dapat memenuhi tujuan pendirian dari lembaga pendidikan yang bermutu.

Dari hasil pengamatan ditunjukkan bahwa masih banyak lembaga PAUD yang tidak memenuhi standar mutu minimal, yaitu sebesar 20\%. Pembinaan perlu dilakukan oleh pemerintah sebagai penanggung jawab atas terselenggaranya 
Al-Ishlah: Jurnal Pendidikan - ISSN: 2087-949o (p); 2597-940X (e)

Vol. 11, No. 2 (2019)

pendidikan yang bermutu kepada setiap warga negara tanpa diskriminasi. Pemerintah daerah bekerja sama dengan pemerintah pusat untuk meningkatkan mutu pendidikan sampai ke pelosok negeri, sehingga mutu pendidikan terjamin seperti yang diamanatkan oleh undang-undang.

Keikutsertaan pemerintah dalam mendorong peningkatan mutu pendidikan lembaga PAUD sangat dibutuhkan. Lembaga PAUD, terutama lembaga pemula, biasanya tidak mengerti tentang aspek-aspek penilaian. Apalagi ketersediaan personel pengelola PAUD yang memiliki kompetensi yang cukup di tingkat desa sangat terbatas.

Undang-undang Nomor 20 Tahun 2003 tentang Sistem Pendidikan Nasional mengamanatkan dengan tegas perlunya penanganan pendidikan anak usia dini. Pada pasal 1 butir 14 dikatakan bahwa: "Pendidikan anak usia dini adalah suatu upaya pembinaan yang ditujukan kepada anak sejak lahir sampai dengan usia enan tahun yang dilakukan melalui pemberian rangsangan pendidikan untuk membantu pertumbuhan dan perkembangan jasmani dan rohani agar anak memiliki kesiapan dalam memasuki pendidikan lebih lanjut." Selanjutnya, pada pasal 28 dinyatakan bahwa pendidikan anak usia dini dapat diselenggarakan melalui jalur pendidikan formal, nonformal, dan informal. PAUD pada jalur pendidikan nonformal dapat berupa kelompok bermain (KB), taman penitipan anak (TPA), atau bentuk satuan PAUD lain yang sederajat.

Pendidikan anak usia dini merupakan salah satu bentuk penyelenggaraan pendidikan yang dititikberatkan pada pengembangan pembentukan perilaku/pembiasaan yang meliputi: (1) perkembangan nilai-nilai agama dan moral; (2) perkembangan sosial emosional, kemandirian, dan kemampuan dasar. Perkembangan kedua meliputi: (a) perkembangan bahasa, (b) perkembangan kognitif, dan (c) perkembangan fisik motorik.

\section{Faktor-Faktor Dominan yang Belum Memenuhi Kriteria Kelulusan Akreditasi}

Dari 22 butir status major dalam rubrik penilaian akreditasi PAUD terdapat beberapa butir yang menjadi faktor dominan tidak terpenuhinya standar nasional pada lembaga-lembaga PAUD di Kecamatan Bengkalis.

Untuk mempercepat pengupayaan peningkatan mutu sesuai butir akreditasi, pembinaan dilakukan dengan menekankan butir-butir yang termaktub dalam rubrik penilaian akreditasi PAUD. Para pengurus lembaga PAUD pada umumnya masih belum mengerti cara mengelola butir-butir tersebut sehingga dapat memenuhi kriteria minimal. Pembinaan terhadap lembaga PAUD dapat berupa pelatihan, grup diskusi, sosialisasi peraturan, bantuan dana, dan lain-lain. Faktor-faktor dominan ini harus menjadi perhatian khusus mengingat lembaga PAUD banyak yang tidak memenuhi standar nasional. Hal ini akibat 
Al-Ishlah: Jurnal Pendidikan - ISSN: 2087-949o (p); 2597-940X (e)

Vol. 11, No. 2 (2019)

ketidaktahuan akan keberadaan 22 butir tersebut yang termasuk dalam kriteria penilaian, sehingga para pengelola lembaga tidak membuat atau tidak mengetahui cara membuat dan mengelolanya.

Selain itu, guru-guru dan kepala masih belum mampu menganalisis keterkaitan antara instrumen akreditasi, petunjuk teknis pengisian instrumen akreditasi, dan instrumen pengumpulan data dan informasi pendukung (Ramdani, Witono dan Sukardi, 2018: 36).

Menurut Fithri dan Anggraini (2018: 13), kegiatan akreditasi yang dilakukan belum dipahami secara penuh oleh seluruh PAUD yang ada di kecamatan. Sosialisasi yang masih kurang memberikan peluang kepada sekolah untuk tidak meningkatkan mutu atau kualitas pelayanan kepada anak didik. Keterbatasan sarana dan prasarana yang ada serta keterbatasan pengetahuan administrasi di lembaga menjadikan penilaian akreditasi yang berlangsung tidak sesuai dengan harapan. Masih terbatasnya biaya operasional di Lembaga juga menyebabkan gerak percepatan perubahan akreditasi menjadi lambat.

Faktor yang paling sering muncul sehingga membuat rendah capaian nilai akreditasi lembaga PAUD di Kecamatan Bengkalis adalah butir 19 yang berisikan satuan PAUD memiliki deskripsi tugas personalia sesuai bagan struktur organisasi. Dari hasil temuan lapangan, hampir seluruh lembaga PAUD tidak menyusun bagan struktur organisasi lengkap dengan tugas personalia. Personel lembaga lebih cenderung berdasarkan intuisi saja dalam melaksanakan tugasnya. Hal ini sangat berpengaruh pada kinerja lembaga karena masing-masing personel tidak memiliki rasa tanggung jawab terhadap beban kerja. Seharusnya, pengelola sebuah lembaga menyusun dan membagi tugas dan fungsi masing-masing jabatan dalam lembaga sehingga menghasilkan beban kerja yang merata dan profesional sesuai dengan kompetensi masing-masing personel.

Faktor kedua yang membuat rendahnya capaian nilai akreditasi lembaga PAUD di Kecamatan Bengkalis adalah butir 17 yang berisikan satuan PAUD memiliki rencana kerja tahunan yang mengandung unsur tujuan, target, sasaran, kebijakan, program kegiatan, dan pembiayaan. Rencana kerja tahunan yang matang dibutuhkan untuk melaksanakan program. Rencana kerja ini tidak bisa dirancang secara mendadak. Rencana kerja tahunan harus disusun sebagai hasil musyawarah di dalam lembaga terhadap program-program yang akan dilaksanakan sehingga membuat lembaga memiliki target yang akan dipenuhi selama setahun. Dengan demikian, pelaksanaan program, terutama kegiatan khusus, dapat terlaksana dengan baik. Rencana kerja tahunan harus disusun terjadwal.

Faktor ketiga yang membuat rendahnya capaian nilai akreditasi lembaga PAUD di Kecamatan Bengkalis adalah butir 5 yang berisikan aspek-aspek pengembangan pada pelaksanaan pembelajaran harian secara terpisah dalam 
Al-Ishlah: Jurnal Pendidikan - ISSN: 2087-949o (p); 2597-940X (e)

Vol. 11, No. 2 (2019)

program PAUD. Aspek-aspek pengembangan ini berisi butir aspek pengembangan nilai agama moral, kognitif, sosial emosional, bahasa, fisik dan motorik, serta seni. Dari 6 aspek tersebut, kriteria minimal yang harus dipenuhi adalah 4 butir. Pada umumnya, temuan lapangan menunjukkan aspek yang dipenuhi kurang dari 4 butir. Kegiatan pengembangan suatu aspek dilakukan secara terpadu dengan aspek yang lain menggunakan pendekatan tematik.

Faktor keempat yang membuat rendahnya capaian nilai akreditasi lembaga PAUD di Kecamatan Bengkalis adalah butir 6 yang berisikan rencana kegiatan mingguan (RKM). RKM harus memuat tujuan pembelajaran, strategi pembelajaran, materi pembelajaran, dan alokasi waktu. RKM harus dalam bentuk tertulis. Kriteria minimal yang harus dipenuhi adalah RKM memuat tujuan pembelajaran, materi pembelajaran, dan alokasi waktu. Bila salah satu dari kriteria minimal ini tidak terpenuhi, RKM tersebut dinyatakan tidak memenuhi kriteria atau tidak dinilai.

Faktor kelima yang membuat rendahnya capaian nilai akreditasi lembaga PAUD di Kecamatan Bengkalis adalah butir 7 berisikan program PAUD yang harus memiliki program holistic integrative, mencakup kesehatan, gizi, rangsangan pendidikan, pengasuhan, dan perlindungan. Dari kelima aspek tersebut, kriteria minimal yang harus dipenuhi adalah 3 aspek. Bila kurang dari 3 aspek, kriteria tersebut dinyatakan tidak terpenuhi atau tidak dinilai.

Dengan terurainya kelima faktor dominan ini, diharapkan para pengurus lembaga segera dapat melakukan langkah cepat untuk memperbaiki dan mempersiapkan materi, sehingga pada saat dilakukan penilaian oleh tim akreditasi, lembaga PAUD yang dimiliki sudah memenuhi kriteria standar nasional dan layak untuk menjalankan program pendidikannya.

Untuk mempercepat peningkatan nilai capaian akreditasi sekolah perlu didukung oleh pendampingan dan pembinaan yang dilakukan badan akreditasi yang bekerja sama dengan dinas pendidikan terkait, sehingga pihak penyelenggara satuan PAUD dapat mengerti hal yang harus dikerjakan dalam penyempurnaan lembaga yang dimiliki.

Adanya program pendampingan dan pembinaan ini berdampak terhadap peningkatan pemahaman sekolah mitra terkait akreditasi sehingga dapat menumbuhkan kesadaran serta meningkatkan tanggung jawab sekolah mitra untuk meningkatkan status akreditasi sekolah (Rahman, et al., 2017: 59). 
Al-Ishlah: Jurnal Pendidikan - ISSN: 2087-949o (p); 2597-940X (e)

Vol. 11, No. 2 (2019)

\section{SIMPULAN}

Sistem pengelolaan PAUD di Kecamatan Bengkalis yang memenuhi kriteria standar nasional lulus akreditasi sebesar $80 \%$ dan yang belum lulus akreditasi adalah 20\%. Faktor dominan yang belum terpenuhi dalam kriteria standar nasional sistem pengelolaan PAUD di Kecamatan Bengkalis adalah: (1) satuan PAUD belum memiliki deskripsi tugas personalia sesuai bagan struktur organisasi; (2) satuan PAUD belum memiliki rencana kerja tahunan yang mengandung unsur tujuan, target, sasaran, kebijakan, program kegiatan, dan pembiayaan; (3) aspek-aspek pengembangan pada pelaksanaan pembelajaran harian secara terpisah dalam program PAUD belum mencukupi; (4) satuan PAUD tidak memiliki rencana kegiatan mingguan (RKM); (5) satuan PAUD belum memiliki program holistic integrative yang mencakup kesehatan, gizi, rangsangan pendidikan, pengasuhan, dan perlindungan.

\section{DAFTAR PUSTAKA}

Fatimah D. F., dan Rohmah N. (2016). Pola Pengelolaan Pendidikan Anak Usia Dini di PAUD Ceria Gondangsari Jawa Tengah, Jurnal Manageria: Jurnal Manajemen Pendidikan Islam. 1 (2), 247-273.

Fithri R., dan Anggraini W. (2018). Peningkatan Mutu Sekolah TK Melalui Akreditasi Se-Kecamatan Pucuk Rantau Kabupaten Kuantan Singingi, PAUD Lectura: Jurnal Pendidikan Anak Usia Dini, 2(1):1-15.

Mukminin A, dan Cahyani M. D. (2017). Pengelolaan Pendidikan Anak Usia Dini Pemula di Kecamatan Grabag Kabupaten Purworejo: Journal of Nonformal Education, 3 (1), 47-52.

Peraturan Menteri Pendidikan dan Kebudayaan Republik Indonesia Nomor 137 Tahun 2014 Tentang Standar Nasional Pendidikan Anak Usia Dini, Sekretariat Negara Republik Indonesia, Jakarta.

Rahman M. H., Saprudin, Mubarak H., dan Hamid F. (2017). Evaluasi Program Ibm Pendampingan Penyusunan Borang Akreditasi bagi Sekolah Dasar di Kota Ternate, Titian Ilmu: Jurnal Ilmiah Multi Sciences, 9(2), 59-65.

Ramdani A., Witono A. H., dan Sukardi. (2018). Pelatihan Pengisian Instrumen Akreditasi Untuk Peningkatan Mutu Evaluasi Diri Sekolah/Madrasah 
Al-Ishlah: Jurnal Pendidikan - ISSN: 2087-949o (p); 2597-940X (e)

Vol. 11, No. 2 (2019)

pada Kelompok Kerja Madrasah Aliyah Wilayah IV: Jurnal Pengabdian Magister Pendidikan IPA, 1 (1): 32-36.

Sumaryanto P. (2014). Implementasi Kebijakan Kelembagaan Paud (Studi Kualitatif Deskriptif pada PAUD di Jakarta Utara): Jurnal Edukasi Islami: Jurnal Pendidikan Islam, 3 (5), 533-549.

Undang-Undang Republik Indonesia Nomor 20 Tahun 2003 Tentang Sistem Pendidikan Nasional, Sekretariat Negara Republik Indonesia, Jakarta. 